\title{
Gender Relations at the Digitalised Workplace: The Interrelation Between Digitalisation, Gender, and Work
}

\section{Bettina Kohlrausch, Lena Weber}

\begin{abstract}
Innovative leaps in digital technology alongside changing gender roles in society may open a window of opportunity to renegotiate gendered work patterns. The main question addressed in this article is the extent to which digitalisation holds the potential to reorganise gendered work relations, and if so why. First, we elaborate on the interrelation between work and gender in capitalist societies. Our main argument is that digitalisation is shifting the boundaries between paid and unpaid labour with far-reaching repercussions for women and men. Second, we will identify core digitalisation processes capable of overcoming or changing gendered work patterns. These include automation, the platform economy, and the interactive processes by which a value is assigned to work. We discuss these three processes and their implications for gender inequalities by means of examples based on current literature.
\end{abstract}

Keywords: gendered work pattern, digitalisation, digital capitalism

Kohlrausch, Bettina, Weber, Lena. 2020. Gender Relations at the Digitalised Workplace: The Interrelation Between Digitalisation, Gender, and Work. Gender a výzkum / Gender and Research 21 (2): 13-31, http://dx.doi.org/10.13060/gav.2020.010.

Digitalisation is often considered a primary driver of future social, economic, and cultural changes, potentially even on par with the first Industrial Revolution (Staab 2016). The process of digitalisation is mainly associated with new opportunities to interlink machines with machines or human beings via the internet and with algorithmic decision-making. The term 'digital capitalism' captures the accelerating changes that modern societies are currently facing (Brynjolfsson, McAfee 2014; Schiller 2000; Pasquale 2015; Staab 2016). Key characteristics of this 'new age' of capitalism are

\footnotetext{
1 We thank the anonymous reviewers for their careful reading of our manuscript and many insightful comments and suggestions. We feel that this has resulted in a stronger manuscript.
} 


\section{NV STATI / ARTICLES}

the exponential increase in the performance of information and communication technology (processors, memory, etc.), the development of new technologies (such as smartphones, 3-D printing, or robotics), the collection and evaluation of large amounts of data, the further development and increased usability of artificial intelligence, and finally digital networking of people and things. New business strategies in the platform economy increasingly focus on the commercial exploitation of client and user data with far-reaching consequences for the reorganisation of production, reproduction, and work. Within this, behaviour data (GPS tracking data) can be profited from financially (by Google) and formerly unpaid work and open source technology can be commercialised, as a precondition for being digitalised.

Innovative leaps in technology, alongside changing gender roles in society, may open a window of opportunity to renegotiate gendered work patterns (Carstensen 2019; Wajcman 2004). We argue that the digital organisation and regulation of data are of formative significance for the organisation of production, work, gender relations, and society at large. Scholars in the field of digital capitalism highlight the enormous impact digital applications have on the separation of productive and reproductive labour (Huws 2014; Staab 2016), this dualism between productive and reproductive labour is strongly interwoven with the asymmetric gender order in Western society. Changes in this separation of work spheres are therefore closely interlinked with transformed gender relations.

The main question addressed in this article is the extent to which digitalisation holds the potential to reorganise gendered work relations and if so why. We provide a systematic analysis of the relationship between gender and the digitalisation of work by creating a conceptual heuristic. Our analysis focuses on how gender assignments and the patterns of the gender division of labour are shaped, negotiated, or affected by digitalisation. First, based on the feminist critique of capitalism, we will elaborate on the interrelation between work and gender in capitalist societies. Second, we will identify the core digitalisation processes capable of overcoming or changing gendered work patterns. These include automation (2.1), the platform economy and gender-exclusive power mechanisms (2.2), and the processes of doing gender in digital work settings and technologies (2.3). We will discuss these three mechanisms by means of examples based on current literature. In our conclusion, we will evaluate emerging trends and findings from a feminist perspective. Our main argument is that digitalisation shifts the boundaries between paid and unpaid labour, which are connected with gendered division of work, and this will reinforce unequal gendered work pattern. 


\section{Feminist critics of capitalistic work organisation: historical and structural preconditions for digitalisation}

One important strand of feminist theory has always pointed to the interrelationship between capitalism and patriarchy. The development of a reproductive sphere has been a critical requirement to increase (male) productivity on the shop floor, in the productive sphere, and thus implement a more efficient mode of capitalist production. Critical feminist analyses of capitalism argue that male control over women's labour power, thus the hierarchical relationship between genders, relies on gendered work organisation and the division of labour between reproduction and production (Hartmann 1979; Becker-Schmidt 2002; Eisenstein 1979).

In our theoretical framework, we refer to the German feminist theorist Regina Becker-Schmidt (2002; 2003; 2007), who describes the gendered division of labour in capitalism. Regina Becker-Schmidt's approach is insightful as it explains that the division between reproductive and productive labour and paid and unpaid labour, which is essential for the capitalist mode of production, is linked to the hierarchical relationship between genders. The simultaneous separation and interdependence of the two 'spheres of labour' is a highly conflicting arrangement, one that is deeply ingrained in the capitalist gender order: 'Although they are separated from one another, they are bound together; although they are bound by reciprocity, they are separated by antagonism' (Becker-Schmidt 2002:36). Some analyses of digital capitalism suggest that this central dualism between productive and reproductive work is eroding and/or is being reconfigured by the digital economy and work. BeckerSchmidt $(2002,2003$, 2007) shows that the division between productive/public and reproductive/private work in the realm of the transformation from a feudalistic society to industrialised capitalism is accompanied by a close association between reproductive and unpaid work on the one hand and femininity on the other. Skills and abilities that seem to be necessary in this sphere, such as emotionality, sensitivity, and empathy are deemed to be typical female. Paid and productive work is highly associated with masculinity and attributes such as being powerful, assertive, strong, and rational are deemed to be typical male. Gender-specific attributions were and to some extent still are regarded as given by nature, even if this has been proven not to be true.

Existing feminist theoretical analyses of digital labour often focus primarily on the incorporation of immaterial labour into the market (Gregg, Andrijasevic 2019; Huws 2019; Jarrett 2014, 2016). However, this is a theoretical shortcoming since the digitalisation of work affects gender inequalities on several levels and in multiple fields. The potential of Becker-Schmidt's approach is her focus on the contradictory pattern of women's socialisation within the productive and reproductive sphere. 


\section{NV STATI / ARTICLES}

The focal point of her argument is that devalued and unpaid work is attributed and linked to women and femininity in modern capitalism (Becker-Schmidt 2002, 2003). Based on Becker-Schmidt's perspective, this conflicting socialisation of women into the spheres of paid and unpaid work is indicated by three main characteristics, which will guide us in our further examination of the literature about the potential gender-unequal outcome of digital labour. Therefore, we will briefly present here the central arguments of these three main characteristics.

\section{The gendered division of productive/paid and reproductive/unpaid labour}

Salary defines the dividing line between productive or paid and reproductive or unpaid labour. Reproductive labour has long been provided primarily by women (wives), who have been excluded from the labour force in Western society. This unequal gender order is and was related to and became integrated into the German welfare state system, where men have been considered the 'male breadwinner' in the family (Esping-Andersen 1990; Pfau-Effinger 2005). ${ }^{2}$ These arrangements are reinforced by patterns of collective bargaining. Collective bargaining has had a strong gender bias as the male segments of the labour market are covered to a much greater extent by collective agreements than the female ones.

Becker-Schmidt (2002) states that the demands resulting from reproductive work, on the one hand, and productive work, on the other, structurally contradict each other. Care work, with its orientation towards the needs and intentions of others, is structured in a profoundly different manner than the sphere of employment, where profit, competition, and efficiency reign as the guiding principles. Therefore, reconciling employment with private life is more conflicted for women than it is for men (Jurczyk 1998). While private and working life add up in a positive way for hegemonic masculinity and men, femininity and women are confronted more strongly with the question of whether and in which phases they should give preference to either one or the other (Becker-Schmidt 2002: 41-42).

\section{Horizontal gender segregation of the labour market}

Gender segregation on the labour market is highly interrelated with the processes of 'doing gender' (West, Zimmerman 1987). Gender research has shown that each task, activity, or type of employment and work field has its own underlying gender belief system, which gives credibility to the employees and makes 'doing gender while doing work' part of their work task. 'Gender-typed work has different meanings for

\footnotetext{
2 We have analysed the changes from a German point of view, since welfare-state institutions are shaped and influenced by nation states. However, the effects of digitalisation are spreading on a global labour market. Therefore, we point out the implications at the given points.
} 
women and men, however, because of differences in the cultural valuation of behavior considered appropriate to each gender' (Leidner 1991: 154). The strong connection between femininity and reproductive work, such as childbearing and care for elderly people, draws a line between the spheres of paid and unpaid work, but it also has implications for gendered labour market segregation and the devaluation of women's work within the productive sphere. 'Horizontal segregation refers to segregation across the manual-non-manual divide, specifically women's underrepresentation in manual occupation (e.g. manufacturing, craft) and their overrepresentation in nonmanufacturing occupations (e.g. semi-professional, clerical, sales, service) ${ }^{\prime 3}$ (Charles 2003: 269). Thus, 'women's labour' is often low paid and entails no or precarious social protection and less bargaining power (Campbell, Vosko, MacDonald 2009). Even though women work in comparable or the same positions as men, they can be unfairly compensated, which is referred to as the 'gender pay gap' (Scheele 2007).

\section{Vertical gendered segregation of the labour market}

'Vertical segregation refers to hierarchical inequality, specifically men's domination of the highest-status occupations within the manual and non-manual sectors of the economy' (Charles 2003: 269). Vertical labour market segregation is entangled with the horizontal gender segregation of work in capitalist societies. The socialisation of women within the sphere of reproduction weakens their position within the realm of productive work. The way women are primarily ascribed with responsibility for unpaid care work in private life establishes a culture of 'male primacy', since paid work is more valued in capitalism than unpaid work. The formal and operational organisation of work, in the form of full-time working hours or the organisation of careers according to the principle of seniority, are often incompatible with reproductive work. Moreover, the classical understanding of a workplace is that of a formal organisation, which is characterised by clearly defined objectives, means-end rationality, job descriptions, rules of membership, hierarchies, decision-making channels, and labour division. As feminist scholars have shown, this seemingly 'gender-neutral' definition of formal organisations is androcentric (i.e. Acker 1990). The organisation of labour within the workplace reflects the gender division of labour in society in many ways. Female employees are underrepresented in leading and top positions, whereas they are mostly found in assistant jobs and jobs with low qualifications in work organisations (Keane, Russell, Smyth 2017). Gender research has shown that the formal barriers

3 The distinction between manual and non-manual occupations was introduced by the International Labour Organization (ILO) and their International Standard Classification of Occupation (ISCO). Femaledominated 'care' work services are classified into non-manual occupations (health care, social, cultural and physical services, teaching), whereas domestic work (cleaning, preparation of food, and helping) is manual. Therefore, the gendered classification of the occupations is crosswise to the ISCO. 


\section{NV STATI / ARTICLES}

women have faced are dissolving or have been removed in most organisations, with many organisations declaring their commitment to gender equality and diversity (on academia see Riegraf, Weber 2017), while informal processes and gender belief systems persist. This in turn structures gender relationships inside and outside the labour market by spreading the general belief that 'men's traits are more valuable' and women are generally less technically competent (Charles 2003: 270).

In recent decades, feminist analysis of capitalism has referred to changes in gendered work arrangements, such as the blurring of boundaries between the productive and reproductive spheres and between paid and unpaid labour as a result of the neoliberal shift in society (Fraser 2009), the increase in the number of women in the paid workforce, the greater acceptance of gender equality in at least some societies, and the globalisation of labour markets. Economic rationality is one important precondition for the distribution and adoption of digital labour. We argue in this article that digitalisation will reinforce certain gender inequalities and push forward a gendered re-negotiation and organisation of work. First, typical women's work is less likely to be affected by automation, whereas typical men's work may be devalued and deregulated. This can be understood to mean that the opportunities and risks of the male and female labour force are becoming more aligned. Second, the platform economy creates new work forms, which seem to extend the disadvantages that women already face in offline employment. Third, typical gendered ascriptions and stereotypes will become inscribed in the construction of seemingly 'objective' or 'neutral' digital technics, which reinforces unequal gender work arrangements as they become invisible in a new way.

\section{Gendered division of productive and reproductive labour in digital capitalism}

The digital transformation of production and the labour market is accelerating and reinforcing the processes that blur the boundaries between paid and unpaid work (Huws 2014; Staab 2016). Contemporary capitalist business models tend to build upon digital technologies, which are likely to restructure capitalist patterns of production and, as a result, the gender relations underpinning them (see above). The leading question in our analysis is whether technological changes will dilute or exacerbate the existing mechanisms of gender inequalities. We identify three processes of digitalisation as the driving forces that are changing the relationship between the productive and reproductive spheres.

First, digitalisation accelerates the automation and optimisation of value chains. This reorganisation of production might imply a revaluation of tasks, and competences, 
as tasks that were formerly central to the organisation of industrial production could be automated. This could lead to a revaluation of manual and non-manual tasks, especially non-automatable female-dominated personal services and domestic work, which could become more highly valued (Dengler, Matthes 2018; Piasna, Drahokoupil 2017).

Second, digitalisation enables and facilitates the establishment of new databased business models known as online platforms or a platform economy (BergvallKåreborn, Howcroft 2014; Codagnone, Karatzogianni, Matthews 2019; Graham, Hjorth, Lehdonvirta 2017; Pesole et al. 2018; Poutanen, Kovalainen, Rouvinen 2020). The existence of the platform economy is accompanied by a decline in standard employment relationships and an increase in the formalisation of work, which has highly gendered implications. Third, the implementation of algorithms, artificial intelligence, cyber-physical systems, and digital applications restructure interaction processes at work at a micro level, which may have the potential to destroy, reproduce, shift, or negotiate 'doing gender' (West, Zimmerman 1987).

\section{Automation: restructuring the gendered segregation of the labour market}

Automation by algorithms, cyber-physical systems, and machine learning is one of the driving forces behind the restructuring of the labour market because it facilitates the substitution of tasks or even whole occupations and their replacement with robotic assistant systems and algorithms. Neither automation nor substitution are new developments, but both have been accelerated by digitalisation. However, '[w]hereas the technologies that drove automation in the past required clear instructions in controlled environments to substitute for human endeavour, new technologies are now increasingly able to act and problem-solve independently, inferring the appropriate solution or actions on the basis of external inputs, and "learning" as they do so' (Lawrence, Roberts, King 2017: 6). We argue that automation has led to a revaluation of 'male' and 'female' work, reinforcing mutual transitions between paid and unpaid work (Huws 2014: 170).

Bonin et al. (2015) conclude that about $12 \%$ of jobs are likely to become substituted in Germany and $9 \%$ in the United States. Scholars agree that lower-skilled tasks are more likely to be substituted. Whether women or men are more likely to be threatened by automation depends on the gender-specific structure of qualification and segmentation within the respective labour market. For Germany, Dengler and Matthes (2016) found a higher risk of substitution in the case of men at all levels of qualification. In low-skilled jobs, the potential of substitution in the case of men (54\%) is significantly higher than it is in the case of women (37\%). For men, the potential decreases as the level of requirements for a job increases. The opposite is true for women: the potential in low-skilled jobs is lower than that in skilled jobs 


\section{NV STATI / ARTICLES}

and only decreases in management positions to about the same extent as it does for men. The main explanation for this is the horizontal segregation of men and women in the labour market: women make up most of the employees in social and cultural services, which are more resistant to automation (e.g., in the care sector, certain tasks can be substituted but probably not whole occupations, since caring itself can best be provided by human beings), whereas men make up the majority in technical jobs, where there is greater substitution potential in lower-level jobs. Empirical evidence on how the gendered occupation structure is already affected remains inconclusive. After comparing job growth and destruction between 2011 and 2015, Piasna and Drahokoupil (2017: 319), who studied the European labour market, conclude that no developments until now 'signal a major break with the traditional division between "female" and "male" jobs' due to digitalisation. However, if the authors take the task content into account (repetitive vs. complex tasks) and not the occupation field, they see that women 'exhibit a faster growth in share of non-routine, analytic and interpersonal tasks' (Piasna, Drahokoupil 2017:320). So far, we have seen the relatively small development of women moving into the better-off sectors of the labour market, but a redistribution of the labour market may be coming - at least for some women, those from a higher socio-economic background.

Kurz et al. (2019) argue that the amount of substitution depends on bargaining power. For Germany, they show that powerful unions have already negotiated instruments for an active labour market policy aimed at safeguarding the jobs of primarily male workers in the car industry. In contrast, there is no comparable lobby for the femaledominated banking sector, which is highly affected by automation. Women are less often enrolled and employed in technical studies and professions (European Commission 2019). Yet technical skills may become the gateway to prestigious positions in the digital age, the ones in which people participate in decisions about who owns data and who is allowed to put a value on data. If women remain less involved in technical knowledge production and have less power over digital tools, the processes of horizontal and vertical segregation are very likely to intensify.

However, both women and men will increasingly face the challenge of managing transitions across occupations. A key prerequisite for accomplishing this challenge is access to continuing education. Recent OECD data (2019) on this topic revealed that, independent of socio-demographic factors and the characteristics of an employment contract, women have fewer opportunities to participate in continuing education than men, even though their willingness to participate is much higher. Moreover, in absolute numbers, the participation of women in continuing education is even lower since they work more often in part-time jobs and on temporary employment contracts, which hampers access to continuing education. Here, existing disadvantages on the labour market are likely to be reinforced. 
Currently, it is still open to debate whether automation will lead to a redistribution of the gendered labour market. There are hints that women's and men's social positions on the labour market are aligned; women's work is less likely to be affected by substitution, whereas men's work is becoming devalued and deregulated by automation. Further, it is not clear if female-dominated care and domestic work, which is more resilient to automation, will based on this be upgraded in society or devalued, because it is not linked to digital skills.

\section{Platform economy, digital workplaces, and gender inequalities}

In this article, we seek to shed light on the interrelation between digital business models and gendered work patterns. Keywords include the platform economy, the sharing economy, digital labour, crowdworking, and virtual teams or self-managed teamwork (Kovalainen, Vallas, Poutanen 2020: 1). The emergence of the platform economy had far-reaching consequences for the organisation of work and maybe even for the 'very conception of what it means to have a "job"' (Kovalainen, Vallas, Poutanen 2020: 1), even though it is only a job provider for a select few in society at present (Huws et al. 2017). In an international comparison, Huws et al. (2017) estimated the number of gig workers as between two percent (Sweden) and nine percent (Italy). However, platform work is a fundamental change because it 'decouples' work from institutional structures, which has extensive ramifications even for nongig work (Kovalainen, Vallas, Poutanen 2020: 2). 'Platform firms almost always define themselves purely as intermediaries rather than employers, thus defining their workers as independent contractors or self-employed.' (Kovalainen, Vallas, Poutanen 2020: 5) The definitions of platform providers are manifold. From microtasking platforms and creative competitions to simply intermediate work and workers (Kovalainen, Vallas, Poutanen 2020).

The platform economy provides jobs across the globe 24/7. It can open access to gainful employment for marginalised groups, such as low-skilled or untrained women (Wood et al. 2019). For them, or for women who perceive their main responsibility to be unpaid care work, this could be a step back into the labour market. It offers them flexibility and task variety. There have been discussions as to whether this would improve the reconciliation of private and professional life, especially for working mothers (Jürgens 2019; Wischermann, Kirschenbauer 2015). At this point, the debate reveals a gender bias, since the problems of reconciling private and professional life are primarily considered to be the responsibility of women (Carstensen 2019). Besides that, we know from other flexible work models that they give rise to individualised or private conflicts over time and resources, which tend to work to the disadvantage of women, especially mothers (Hochschild, Machung 2012; Voß, Weiß 2009). 


\section{NV STATI / ARTICLES}

However, the flip side is that platform work is often low paid and involves social isolation and overwork (Wood et al. 2019), which women already tend to experience in offline workplaces (Campbell, Vosko, MacDonald 2009; Rubery 2011). Initial studies on platform workers suggest that only highly skilled workers with special qualifications (predominantly males) benefit from platform work (Huws et al. 2017). Jürgens (2019) stresses that the use of digital technologies to the benefit of employees is a demanding process and depends on the resources that individual employees have at their disposal. However, due to part-time employment and lower skilled jobs, women have less bargaining power (Abendroth, Reimann 2018). Until now, this has meant that bargaining and negotiation problems have been transferred to the private sphere to be solved, making it even harder to make collective or solidary decisions.

For the informal labour market of care and domestic work, where women are highly represented, the platform economy is one way to receive more formalised work in social services (Ticona, Mateescu 2018; Weber 2020). Platforms such as care.com, helpling.de, carelinx.com, and UrbanSitter.com are already widespread. So far, however, the opposite seems to be true in that existing distinctions between powerless care workers and powerful platform companies and clients are reproduced (Ticona, Mateescu 2018). Nevertheless, the potential is there to create a political framework for more formalisation and better working conditions in this already very precarious labour segment.

One feature the new business models have in common is that they break with standard employment relations and ideals, as demonstrated by the example of Uber, a digital platform that matches clients with private or in some way self-employed drivers (Rosenblat, Stark 2016; Scholz 2017). The role of employees with specific rights and duties is diluted in these data-based work models. This has consequences not only for Uber drivers but also for the entire industry. For instance, data-based business models incorporate informal evaluation processes (Turco 2016). The rating and evaluation of the products or services used become part of the business model, and new techniques are developed for performance control (Gerber 2019). Digital systems of reputation and reward create new forms of precarity (e.g. a dependency on client satisfaction). Moreover, platform work reinforces the fragmentation of jobs, which appears to affect women more than men (Piasna, Drahokoupil 2017: 322). More women than men tend to have multiple short-term and part-time jobs in addition to the solo self-employment.

Another strand of research points to the gender (racial etc.) discriminatory effects of the algorithm decision-making on which platform business models are based (Kullmann 2018; Dastin 2018; O'Neil 2017). Humans decide what is fed into the algorithm and the data model that the algorithm will use to solve a matching 
problem - for example, between a driver and someone who needs a car. Algorithms create gender biases through the gendered datasets that they are fed. In the case of machine-learning, the algorithms can detect a gendered usage pattern and create a gender bias if they learn, for instance, that women tend to prefer female drivers. This short example shows that a digital business model can easily incorporate or build upon gendered structures that have emerged in the analogue world and are likely to perpetuate them, since algorithms are often perceived as neutral or objective. In this regard, gender inequalities might even be obscured.

In sum, the platform economy seems to be a workplace where many already existing disadvantages for female employees are transposed into the digital world, largely because there is little institutional employment representation and bargaining power in female-dominated work areas.

\section{Doing gender in a digital work setting}

The theoretical perspective of doing gender while doing work is based on two assumptions that may be disrupted by digital work settings. The first assumption is that doing gender is part of the social interaction between humans. Cultural and social-service jobs are performed in social interactions, but any other occupation can involve social interactions as well as part of professional everyday life. When digital assistant systems, algorithmic decision-making, technologies, and artificial intelligence are employed, these social interactions may be replaced by data communication or may change in fundamental ways. For example, humans now must interact with machines, robots, or technical systems instead of other humans. The institutional setting of the interaction could be 'released' from doing gender because the machine or the robot does not perceive the 'doing gender' behaviour. However, the construction of artificial intelligence ( $\left.\mathrm{O}^{\prime} \mathrm{Neil} 2017\right)$ and techniques and robots (Weber, Bath 2007) include assumptions about gender. One illustrative example is provided by voice assistants, like 'Siri' and 'Alexa'. Not only do they have a female name, they are constructed as subordinate, friendly, and polite females because most people are familiar with interactive arrangements like these from 'feminised' service jobs, which makes it easier for them to adapt to new digital technologies (West, Kraut, Chew 2019: $91 \mathrm{ff}$.). Seemingly, gender-neutral techniques do not treat people fairly and equally (Dastin 2018; O'Neil 2017; Uhlmann, Silberzahn 2014; Silberzahn, Uhlmann, Zhu 2014).

The second assumption is that doing gender is a type of social interaction in a shared physical space, where mutual perception of alter and ego occurs. Obviously, this definition of an interaction must be expanded, as many social interactions now take place via social media platforms and digitally transferred. Again, given that mutual perception is mediated, stereotypes about gender could be overcome, but 


\section{NV STATI / ARTICLES}

the existing evidences from literature rather suggest the reinforcement of gender stereotyping. ${ }^{4}$

Digital business models create new work areas and forms of work. These, in turn, become part of the process of doing gender; some of these areas and forms of work are attributed to masculinity, others to femininity. Insight can be obtained from how they became valued and commercialised. In this respect, there is a growing debate on the interface between gender and media studies about how digital immaterial labour is linked with gender stereotypes or how women's unpaid immaterial cultural labour is going to be exploited by the digital creative industry. On the one hand, the immaterial labour of blogging, posting, and liking (unpaid work) has a strong link to femininity. These digital platforms can accumulate capital through women's unpaid labour (Arcy 2016:366). Blogging and liking on online platforms are the new 'female-typed' forms of emotional labour of the digital age (Cirucci 2018; Jarrett 2014; Ouellette, Wilson 2011).

Duffy and Pruchniewska (2017) found in their study that female self-employed entrepreneurs feel compelled to develop online profiles that are oriented towards classical concepts of femininity in order to become successful. The authors concluded that the elimination of direct interactions through digital platform work creates uncertainties, which must be compensated for by means of gender overidentification in order to establish credibility, trust, and reliability with customers. Although the hegemonic masculine image of an entrepreneur has several cracks in it and there has been a clear rise in female-typed entrepreneurship (Adkins, Dever 2015; Duffy 2016; Hunter 2016), Duffy and Pruchniewska (2018: 848) detect the persistence of the 'old' offline gender inequalities, which they call the 'digital double bind'. Women must walk the fine line between masculine-assigned business success and the cultural scripts of female self-presentation. Moreover, this finding is also true for start-up culture, where only around fifteen percent are women in Europe (Kollmann et al. 2016).

Although digital work areas have the potential to release social interaction from processes of 'doing gender' or even break up taken-for-granted assumptions about gender-typed skills and capabilities, evidence shows that the hierarchical attribution of gender-typed skills and capabilities in most workplaces is more likely to be reproduced. Studies show that there is a tendency for 'traditional' gender norms to be reinscribed in digital work and digital workers tend to overidentify with gender stereotypes to decrease insecurity in online communication.

\footnotetext{
4 This was already the subject of a virulent discussion at the interface between gender and media studies when the Internet emerged, when the question was whether people would now try to develop genderneutral avatars or profiles or choose to switch their gender.
} 


\section{Conclusion}

The starting point of our argument was the question of how much the changes that labour markets are undergoing in digital capitalism will restructure gender relations. We showed that the feminist analysis of Western capitalism by Becker-Schmidt (2002) is a useful tool for better understanding the fundaments of the entanglement between work and the gender order in capitalism. We showed that the distinction between reproductive and productive work and the subordination of work typically ascribed to be women's work are the basic mechanisms behind the (re)production of gender inequalities. While the division between productive and reproductive work is at the core of the capitalist order, we argue that the reorganisation of work in digital capitalism is aimed at this very core of capitalist work organisation. The guideline for our examination of digital work has been to look at how far the reorganisation of work affects gender relations. We have shown that digitalisation creates or accelerates automation, new business models, and work areas that are capable of dissolving, changing, or reproducing in new forms the separation between productive and reproductive work and consequently also the associated gender dualism and gender inequalities. We examined these processes for the consequences they may hold for the division of paid and unpaid labour and the horizontal and vertical gendered segregation of labour markets.

Concerning automation, we showed that it could lead to the redistribution of gendered vertical and horizontal labour market segregation and for two reasons: First, automation could lead to a reduction in working hours, and that could increase the scope for the redistribution of paid and unpaid work between the genders. Second, men's work is more likely to be affected by substitution than women's work. Women's work (education, childcare, elderly care, health care, domestic care) is more difficult to rationalise or can only be automated to a limited extent. Typical 'female' work could thus gain in relevance, while typical industrial 'male' work, would lose importance, which would change the vertical patterns of gendered labour market segregation. However, women are disadvantaged when it comes to participating in the technical infrastructure of digital capitalism.

New business models and platform work still account for a small proportion of employment. However, this new way of organising work is also contributing to changes in other areas of work not yet organised through platforms. It is becoming apparent that, on the one hand, established standards of social security are being dismantled and, on the other hand, areas of work are being formalised that were previously either not commodified or were informal, and this primarily concerns women's work. We expect a levelling out of employee standards, which will tend to bottom out at a low level and will put women at a greater disadvantage than men. 


\section{NV STATI / ARTICLES}

This is because men's work tends to be better organised in collective agreements than women's work. Vertical labour market segregation would thus be intensified. Moreover, algorithms are the new powerful technology behind these new business models and women rarely participate in the development of algorithms. Furthermore, business models based on co-consumption tend to blur the division of paid and unpaid work, but this is more likely to give rise to new and additional mechanisms for exploiting unpaid work than to overcome existing divisions between productive and unproductive work.

Doing gender processes and human-machine interactions may change digitally mediated work relationships and processes. This could have the potential to overcome the antagonism between female and male work content and tasks and the horizontal and vertical segregation of the labour market. However, as argued above, the initial empirical evidence suggests that the opposite is true. The elimination of direct face-toface interactions that create trust means that individuals, and especially women, tend to overidentify with their gender to establish credibility and trust, thereby reinforcing rather than dismantling or eradicating traditional gender stereotypes.

We have shown that digital capitalism will change the pattern of women's labour market participation and restructure the relationship between productive and reproductive work and labour market segregation. However, we also showed that while this has the potential to create more gender equality in the labour market, there is also the risk that the old modes of discrimination will persist in a new digital form. At the end of the day, the power women have to actively shape the new labour market will determine the outcome of this process.

We therefore identify three main requirements for a more gender-egalitarian digitalisation process. First, women and low-skilled worker must obtain more bargaining power. This concerns the question of whether individuals can manage to create new tools of collectivisation under the conditions of digital labour. Issues relating to labour regulation or the substitution of tasks are therefore not just decided by what is possible in general but are also the result of social negotiation. Thus, more female access to bargaining power will be decisive. Second, there is a huge need for more gender-equal access to information and data construction. Whether work is mainly governed by algorithms and artificial intelligence depends on the extent of the 'information asymmetries that can limit the abilities of the workers to make informed choices' (Kovalainen, Vallas, Poutanen 2020:6). Access to information will thus become a powerful resource. The third requirement is the (re)-qualification of those whose existing qualifications are the jobs and work activities being substituted. This is the central tool for safeguarding employment careers in the digital age.

Our analysis is limited to the trends that we have been able to identify and the special debates that we selected to exemplify our arguments. Until now, most tendencies 
have been difficult to predict because the impacts or changes remain on a normative, regulative, and institutional level that is still shifting, meaning that many developments will only become apparent in the years or decades to come.

\section{References}

Abendroth, A. K., M. Reimann. 2018. Telework and Work-Family Conflict across

Workplaces: Investigating the Implications of Work-Family-Supportive and High-Demand Workplace Cultures. Pp. 323-348 in Contemporary Perspectives on Family Research, in Blair, S. L., J. Obradović (eds.). The Work-Family Interface: Spillover, Complications, and Challenges. Bingley, UK: Emerald Publishing Limited.

Acker, J. 1990. Hierarchies, Jobs, Bodies: A Theory of Gendered Organizations. Gender \& Society 4 (2): 139-158.

Adkins, L., M. Dever (eds.). 2015. The Post-Fordist Sexual Contract: Working and Living in Contingency. Basingstoke: Palgrave Macmillan.

Arcy, J. 2016. Emotion Work: Considering Gender in Digital Labor. Feminist Media Studies 16 (2): 365-368, http://dx.doi.org/10.1080/14680777.2016.1138609.

Becker-Schmidt, R. 2002. Theorizing Gender Arrangements. Pp. 25-48 in Becker-Schmidt, R. (ed.) Gender and Work in Transition: Globalization in Western, Middle and Eastern Europe. Wiesbaden: VS Verlag.

Becker-Schmidt, R. 2003. Umbrüche in Arbeitsbiografien von Frauen: Regionale Konstellationen und globale Entwicklungen. Pp. 101-132 in Knapp, G.-A., A. Wetterer (eds.). Achsen der Differenz. Gesellschaftstheorie und feministische Kritik II. Münster: Westfälisches Dampfboot.

Becker-Schmidt, R. 2007. Geschlechter- und Arbeitsverhältnisse in Bewegung. Pp. 250-268 in Aulenbacher, B., M. Funder, H. Jacobsen, H., S. Völker (eds.). Arbeit und Geschlecht im Umbruch der modernen Gesellschaft: Forschung im Dialog. Wiesbaden: Verlag für Sozialwissenschaften.

Bergvall-Kåreborn, D. Howcroft. 2014. Amazon Mechanical Turk and the Commodification of Labour. New Technology, Work and Employment 29 (3): 213-223.

Bertschek, I., J. Ohnemus, and S. Viete. 2015. Befragung zum sozioökonomischen Hintergrund und zu den Motiven von Crowdworkern: Endbericht zur Kurzexpertise an das Bundesministerium für Arbeit und Soziales. Mannheim.

Bonin, H., T. Gregory, U. Zierahn. 2015. Übertragung der Studie von Frey/Osborne (2013) auf Deutschland: Kurzexpertise Nr. 57 im Auftrag des Bundesministeriums für Arbeit und Soziales. Mannheim: ZEW.

Brynjolfsson, E., A. McAfee. 2014. The Second Machine Age: Wie die nächste digitale Revolution unserer aller Leben verändern wird. Kulmbach: Plassen.

Campbell, I., L. F. Vosko, M. MacDonald. 2009. Gender and the Contours of Precarious Employment. New York: Routledge.

Carstensen, T. 2019. Verunsichtbarung von Geschlechterungleichheiten? Digitalisierte Arbeit zwischen Rhetoriken neuer Möglichkeiten und der Reorganisation alter Muster. Pp. 69-87 in Kohlrausch, B., C. Schildmann, D. Voss (eds.). Industrie 4.0 


\section{NV STATI / ARTICLES}

und Digitalisierung von Arbeit: Neue Arbeit - neue Ungleichheiten? Weinheim: Beltz Juventa.

Charles, M. 2003. Deciphering Sex Segregation: Vertical and Horizontal Inequalities in Ten National Labor Markets. Acta Sociologica 46 (4): 267-287, http://dx.doi.org/10.1177/00 01699303464001.

Cirucci, A. M. 2018. A New Women's Work: Digital Interactions, Gender, and Social Network Sites. International Journal of Communication 12: 2948-2970.

Codagnone, C., A. Karatzogianni, J. Matthews. 2019. Platform Economics: Rhetoric and Reality in the 'Sharing Economy'. Bingley: Emerald Publishing. Retrieved 8/11/2020 (https://www.emeraldinsight.com/doi/book/10.1108/9781787438095).

Dastin, J. 2018. Amazon Scraps Secret Al Recruiting Tool That Showed Bias against Women. Reuters online. Retrieved 23/9/2020 (https://eu-recruit.com/jobs/ai-machine-learning/ ?gclid=EAlalQobChMlvbbrwOr-6wIVjqmyChOzzAldEAAYASAAEgK-NPD_BwE).

Dengler, K., B. Matthes. 2016. Auswirkungen der Digitalisierung auf die Arbeitswelt: Substituierbarkeitspotenziale nach Geschlecht. Aktuelle Berichte No. 24. Nürnberg: Institut für Arbeits-und Berufsforschung.

Dengler, K., B. Matthes. 2018. The Impacts of Digital Transformation on the Labour Market: Substitution Potentials of Occupations in Germany. Technological Forecasting and Social Change 137: 304-316, http://dx.doi.org/10.1016/j.techfore.2018.09.024.

Duffy, B. E. 2016. The Romance of Work: Gender and Aspirational Labour in the Digital Culture Industries. International Journal of Cultural Studies 19 (4): 441-457, http://dx.doi. org/10.1177/1367877915572186.

Duffy, B. E., U. Pruchniewska. 2017. Gender and Self-Enterprise in the Social Media Age: a Digital Double Bind. Information, Communication \& Society 20 (6): 843-859, http:// dx.doi.org/10.1080/1369118X.2017.1291703.

Eisenstein, Z. R. (ed.). 1979. Women's Studies, Political Science. Capitalist Patriarchy and the Case for Socialist Feminism. New York: Monthly Review Press.

Esping-Andersen, G. 1990. The Three Worlds of Welfare Capitalism. Princeton, NJ: Princeton University Press.

Fraser, N. 2009. Feminism, Capitalism and the Cunning of History. New Left Review (2009) 56: 97-117.

Gerber, C. 2019. Brave New Digital Work? New Forms of Performance Control in Crowdwork. Pp. 121-143 in Research in the Sociology of Work, in Vallas, S. P.,

A. Kovalainen (eds.). Work and Labor in the Digital Age. London: Emerald Publishing.

Graham, M., I. Hjorth, V. Lehdonvirta. 2017. Digital Labour and Development: Impacts of Global Digital Labour Platforms and the Gig Economy on Worker Livelihoods. Transfer: European Review of Labour and Research 23 (2): 135-162, http://dx.doi.org/ 10.1177/1024258916687250.

Gregg, M., R. Andrijasevic. 2019. Virtually Absent: The Gendered Histories and Economies of Digital Labour. Feminist Review 123 (1): 1-7, http://dx.doi.org/10.1177/014177891987 8929.

Hartmann, H. I. 1979. The Unhappy Marriage of Marxism and Feminism: Towards a More Progressive Union. Capital \& Class 3 (2): 1-33. 
Hochschild, A. R., A. Machung. 2012. The Second Shift: Working Families and the Revolution at Home. New York: Penguin Books.

Hunter, A. 2016. Monetizing the Mommy: Mommy Blogs and the Audience Commodity. Information, Communication \& Society 19 (9): 1306-1320, http://dx.doi.org/10.1080/ 1369118X.2016.1187642.

Huws, U. 2014. Labor in the Global Digital Economy: The Cybertariat Comes of Age. New York: Monthly Review Press.

Huws, U., N. Spencer, D. Syrdal, K. Holts, A. Graumans. 2017. Work in the European Gig Economy: Research Results from the UK, Sweden, Germany, Austria, the Netherlands, Switzerland and Italy. Brussels: Foundation for European Progressive Studies.

Huws, U. 2019. The Hassle of Housework: Digitalisation and the Commodification of Domestic Labour. Feminist Review 123 (1): 8-23, http://dx.doi.org/10.1177/014177891 9879725.

Jarrett, K. 2014. The Relevance of 'Women's Work': Social Reproduction and Immaterial Labor in Digital Media. Television \& New Media 15 (1): 14-29, http://dx.doi.org/10.1177/ 1527476413487607.

Jarrett, K. 2016. Feminism, Labour and Digital Media: The Digital Housewife. New York, London: Routledge.

Jurczyk, K. 1998. Time in Women's Everyday Lives. Time \& Society 7 (2-3): 283-308, http:// dx.doi.org/10.1177/0961463X98007002007.

Jürgens, K. 2019. Das 'smarte' Leben. Ein Versprechen der Digitalisierung auf dem Prüfstand. Pp. 53-68 in Kohlrausch, B., C. Schildmann, D. Voss (eds.). Industrie 4.0 und Digitalisierung von Arbeit: Neue Arbeit - neue Ungleichheiten? Weinheim: Beltz Juventa.

Keane, C., H. Russell, E. Smyth. 2017. Female Participation Increases and Gender Segregation. ESRI Working Paper. No. 564. Dublin: The Economic and Social Research Institute.

Kollmann, T., C. Stöckmann, S. Hensellek, J. Kensbock. 2016. European Startup Monitor 2016. Essen: Universität Duisburg-Essen Lehrstuhl für E-Business.

Kovalainen, A., S. P. Vallas, S. Poutanen. 2020. Theorizing Work in Contemporary Platform Economy. Forthcoming in Poutanen, S., A. Kovalainen, P. Rouvinen (eds.). Digital Work in the Platform Economy. London: Routledge.

Kullmann, M. 2018. Platform Work, Algorithmic Decision-Making, and EU Gender Equality Law. International Journal of Comparative Labour Law and Industrial Relations 34 (1): 1-21.

Lawrence, M., C. Roberts, L. King. 2017. Managing Automation: Employment, Inequality and Ethics in the Digital Age. IPPR Discussion Paper. London: Institute for Public Policy Research.

Leidner, R. 1991. Serving Hamburgers and Selling Insurances: Gender, Work, and Identity in Interactive Service Jobs. Gender \& Society 5 (2): 154-177, http://dx.doi.org/10.1177/ 089124391005002002.

OECD. 2019. Employment Outlook. Paris: OECD.

O'Neil, C. 2017. Weapons of Math Destruction: How Big Data Increases Inequality and Threatens Democracy. New York: Broadway Books.

Ouellette, L., J. Wilson. 2011. Women's Work: Affective Labour and Convergence Culture. 


\section{NV STATI / ARTICLES}

Cultural Studies 25 (4-5): 548-465, http://dx.doi.org/10.1080/09502386.2011.600546.

Pasquale, F. 2015. The Black Box Society: The Secret Algorithms That Control Money and Information. Cambridge, London: Harvard University Press.

Pesole, A., M. C. Urzí Brancati, E. Fernández-Macías, F. Biagi, I. González Vázquez. 2018. Platform Workers in Europe: Evidence from the COLLEEM Survey. Luxembourg: Publications Office of the European Union.

Pfau-Effinger, B. 2005. Culture and Welfare State Policies: Reflections on a Complex Interrelation. Journal of Social Policy 34 (1): 3-20, http://dx.doi.org/10.1017/ S0047279404008232.

Piasna, A., J. Drahokoupil. 2017. Gender Inequalities in the New World of Work. Transfer: European Review of Labour and Research 23 (3): 313-332, http://dx.doi.org/10.1177/102 4258917713839.

Poutanen, S., A. Kovalainen, P. Rouvinen (eds.). 2020. Digital Work in the Platform Economy. London: Routledge.

Riegraf, B., Weber, L. 2017. Excellence and Gender Equality Policies in Neoliberal Universities. Gender a výzkum / Gender and Research 18 (1): 92-112.

Rosenblat, A., L. Stark. 2016. Algorithmic Labor and Information Asymmetries: A Case Study of Uber's Drivers. International Journal of Communication 10: 3758-3784.

Ross, A. 2013. In Search of the Lost Paycheck. Pp. 13-32 in Scholz, T. (ed.). Digital Labor: The Internet as Playground and Factory. New York: Routledge.

Rubery, J. 2011. Towards a Gendering of the Labour Market Regulation Debate. Cambridge Journal of Economics 35 (6): 1103-26, http://dx.doi.org/10.1093/cje/ber001.

Scheele, A. 2007. Gender and the Quality of Work: An Overview of European and National Approaches. Transfer: European Review of Labour and Research 13 (4): 595-610, http:// dx.doi.org/10.1177/102425890701300406.

Schiller, D. 2000. Digital Capitalism: Networking the Global Market System. Cambridge, MA, London: MIT.

Scholz, T. 2017. Uberworked and Underpaid: How Workers Are Disrupting the Digital Economy. Cambridge, UK: Polity Press.

Silberzahn, R., E. L. Uhlmann, L. Zhu. 2014. Pay As She Goes: For Stereotypically Male Jobs, Women Tend to be Hired by the Hour. Academy of Management Proceedings 2014 (1): 16273, http://dx.doi.org/10.5465/ambpp.2014.16273abstract.

Staab, P. 2016. Falsche Versprechen: Wachstum im digitalen Kapitalismus. Hamburg: Hamburger Edition.

Ticona, J., A. Mateescu. 2018. Trusted Strangers: Carework Platforms' Cultural Entrepreneurship in the On-Demand Economy. New Media \& Society 20 (11): 4384-4404, http://dx.doi.org/10.1177/1461444818773727.

Turco, C. J. 2016. The Conversational Firm: Rethinking Bureaucracy in the Age of Social Media. New York: Columbia University Press.

UhImann, E. L., R. Silberzahn. 2014. Conformity Under Uncertainty: Reliance on Gender Stereotypes in Online Hiring Decisions. The Behavioral and Brain Sciences 37 (1): 103-104, http://dx.doi.org/10.1017/S0140525X13001921.

Voß, G. G., C. Weiß. 2009. Ist der Arbeitskraftunternehmer weiblich? Pp. 65-91 in Lohr, 
K., and Nickel, H. (eds.). Subjektivierung von Arbeit - Riskante Chancen. $2^{\text {nd }}$ ed. Münster: Westfälisches Dampfboot.

Wajcman, J. 2004. TechnoFeminism. Cambridge: Polity Press.

Weber, J., C. Bath. 2007. 'Social' Robots \& 'Emotional' Software Agents: Gendering Processes and De-Gendering Strategies for 'Technologies in the Making'. Pp. 53-63 in Zorn, I., S. Maass, E. Rommes, H. Schelhowe, C. Schirmer (eds.). Gender Designs IT: Construction and Deconstruction of Information Society Technology. Wiesbaden: VS Verlag.

Weber, L. 2020. Digitalisierung, Geschlechtliche Zuweisungsprozesse und De/ Professionalisierung in der Care-Arbeit. Forthcoming in Becker, K., K. Binner, F. Décieux (eds.). Gespannte Arbeits- und Geschlechterverhältnisse im Marktkapitalismus. Wiesbaden: Springer.

West, C., D. H. Zimmerman. 1987. Doing Gender. Gender \& Society 1 (2): 125-151, http:// dx.doi.org/10.1177/0891243287001002002.

West, M., R. Kraut, H. E. Chew. 2019. I'd Blush If I Could: Closing Gender Divides in Digital Skills through Education. Paris: UNESCO.

Wischermann, U., A. Kirschenbauer (eds.). 2015. Geschlechterarrangements in Bewegung: Veränderte Arbeits- und Lebensweisen durch Informatisierung? Bielefeld: transcript. Wood, A. J., M. Graham, V. Lehdonvirta, I. Hjorth. 2019. Good Gig, Bad Gig: Autonomy and Algorithmic Control in the Global Gig Economy. Work, Employment \& Society: A Journal of the British Sociological Association 33 (1): 56-75, http://dx.doi.org/10.1177/ 0950017018785616.

(c) BY-NC Bettina Kohlrausch, Lena Weber, 2020.

(a) BY-NC Institute of Sociology of the Czech Academy of Sciences, 2020.

Prof. Bettina Kohlrausch is Professor for Sociology of Social Transformation and Digitalisation at the University of Paderborn (Germany) and director of the Institute of Economic and Social Research (WSI). Her latest research is on right-wing populism and unequal access to the labour market for pupils of disadvantaged social backgrounds. Contact e-mail: bettina-kohlrausch@boeckler.de.

Dr Lena Weber is a post-doctoral researcher in sociology at the University of Paderborn (Germany). Her current research focuses on digital technologies in care work, especially elderly care, the gendered organisation of care work, and the economisation of higher education, neoliberal universities, and their impact on gender equality policies in different countries. Contact e-mail: leweber@mail.upb.de. 